\title{
Desarrollo de la normativa sismo resistente colombiana en los 30 años desde su primera expedición ${ }^{1}$
}

\author{
Developments in Colombian Regulations for Earthquake Resistance in the 30 Years Since Their \\ Inception
}

\author{
Luis Enrique García ${ }^{(1)}$ \\ y Diseños Ltda. lugarcia@uniandes.edu.co \\ Recibido 8 de septiembre de 2014. Modificado 16 de febrero de 2015. Aprobado 18 de febrero de 2015.
}

(1) M.Sc. Universidad de Illinois Urbana-Champaign, USA. Profesor de cátedra de la Universidad de los Andes y socio y gerente de Proyectos

DOI: http://dx.doi.org/10.16924/riua.v0i41.785

\author{
Palabras clave \\ Códigos de construcción, Colombia, Reglamento NSR-10, \\ reglamentación sismo resistente.
}

\section{Resumen}

El Código Colombiano de Construcciones Sismo Resistentes expedido por medio del Decreto-Ley 1400 de 1984 fue un primer intento de normalización del diseño y construcción de estructuras en el medio nacional y estuvo vigente durante 14 años. Después, fue aprobada por el Congreso de la República la Ley 400 de 1997, al amparo de la cual se expidieron los Reglamentos de Construcción Sismo Resistente NSR-98 (1998), que substituyó al Código de 1984, y la actualización expedida en el 2010 como Reglamento NSR-10, hoy vigente. En este artículo se hace un breve resumen del contenido de la reglamentación sismo resistente colombiana, sus aciertos y los aspectos que aún faltan por implementar. Además, se hace un análisis de los aspectos jurídicos que la afectan cómo la reciente Ley de Bomberos, la microzonificación de ciudades intermedias y grandes, la rehabilitación sísmica de edificaciones indispensables y de atención a la comunidad, entre otros.

\section{Key words}

Building code, Colombia, regulation NSR-10, earthquake resistance regulations.

\begin{abstract}
The Colombian Code of Earthquake Resistant Building, issued via Decree-Law 1400 of 1984, was the first attempt to nationally regulate the design and building of structures, and remained in force for 14 years. Later, the Congress of the Republic approved Law 400 of 1997, under which the Regulations of Earthquake Resistant Building NSR98 (1998) were issued, replacing the 1984 code. In 2010, the updated NSR-10 Regulations were put into place and remain valid today. This article offers a brief summary of the contents of the Colombia Earthquake Resistance Regulations, their successes, and the aspects remaining to be implemented. Furthermore, the legal issues that affect these regulations are analyzed, such as the recent Law of Firemen, the micro-zoning of intermediate-sized and large cities, the earthquake-proofing of critical buildings, and community attention.
\end{abstract}

\section{INTRODUCCIÓN}

Hablaré de la historia de la normativa colombiana y su relación con el tema de los códigos de construcción. Para ello vale la pena empezar con una pregunta ¿qué es un código de construcción? La respuesta es sencilla. Un código de construcción es un contrato social por medio del cual se define nacionalmente un riesgo aceptable para las construcciones y lo que jurídicamente es permitido y lo que no. Esto trae como consecuencia una serie de preocupaciones que es lo que tal vez hoy nos trae a este foro. Sin embargo, un corolario de que sea un contrato social es que lo debe implementar el legislador. Ese es

${ }^{1}$ Este artículo es el resultado de la ponencia presentada por Luis Enrique García en el foro "Los códigos en la construcción en Colombia: Aproximaciones y Aplicaciones", realizado en la Universidad de los Andes el 8 de septiembre de 2014. 
un punto importante ya que, quién está llamado a definir cuáles son las reglas del juego implementadas en un código de construcción es el Congreso de la República.

Históricamente los códigos han sido prescriptivos, fijan unas reglas, lo que se permite hacer y lo que no, pero esto ha ido evolucionando hacia los códigos por desempeño, en los cuales se fijan unos objetivos generales no prescriptivos de desempeño o comportamiento adecuado bajo la responsabilidad de quien desarrolla los proyectos, los diseña, los maneja y los construye con un objetivo final preestablecido. Esto no es nuevo. En 1760 a. de C. Hammurabi en Babilonia (Figura 1) estableció un código con objetivos muy claros. Si un constructor construye una casa y esta se cae y mata al propietario, se condena al constructor y si mata al hijo del propietario, matan al hijo del constructor. Esto es un ejemplo de un código por desempeño.

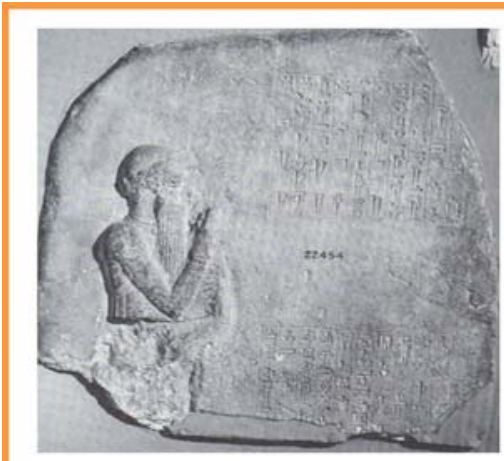

\section{Si un constructor le construye una casa a alguien y no lo hace apropiadamente, y la casa falla y mata al propietario, entonces hay que matar al constructor.}

229. Si mata al hijo del propietario, el se debe matar al hijo del constructor. obtiene la resistencia esperada, ¿de quién es la culpa? ¿Es del fabricante del cemento? ¿Se cumplió el desempeño esperado? ¿Es del usuario? Esto deja un sinnúmero de inquietudes que vale la pena estudiar cuidadosamente. No necesariamente son buenas o mapero coordinadamente y con amplia información sobre las implicaciones que conllevan. códigos de construcción la dio el profesor Hardy Cross (1985-1959), que fue el inventor del método de distribución de momentos en la década de 1930, por medio del cual se logró romper la barrera de poder analizar estructuras complejas utilizando regla de cálculo. Él dijo claramente que un código de construcción es "un instrumento para mantener a raya a los pícaros y a los de construcción, especialmente cuando esta reducción de la especificación introduce un peligro para la vida.

A partir de la década de 1970 nació una preocupación relacionada con la complejidad de los códigos de construcción. La crítica se refería a un exceso de reglamentación. Por ejemplo, nuestra norma NSR-10 tiene casi del orden de dos mil páginas, y esto la hace compleja. El país hizo un experimento hace algunos años de generar un código de construcción en concreto reforzado para edificios hasta de cinco pisos denominado IPS-1, el cual se volvió el documento que más vendió el American Concrete Institute (ACI), en su traducción al inglés, en el 2002. Simplemente son unas reglas de diseño muy simples, no se necesita computador para aplicarlo, con una calculadora manual se diseña un edificio de hasta cinco pisos, seguro, sin problemas, está permitida por el Reglamento NSR-10 y es un ejemplo de respuesta a la crítica de la complejidad.

\section{¿QUÉ CUBREN LOS CóDIGOS DE CONSTRUCCIÓN?}

Históricamente el contenido estuvo siempre muy ligado con lo estructural, luego aparecieron otros temas que definitivamente es conveniente cubrir. Esto en parte, en una serie de países, vino de las compañías de seguros por el tema de incendio y se introdujeron temas como los medios de evacuación, la prevención y el control de fuego, muchos de los cuales fueron los determinantes de los códigos. Ese conjunto es lo que nos lleva al contenido de un código de construcción moderno, con adiciones recientes como la integridad estructural para evitar colapso progresivo, la conservación de energía, la sostenibilidad, y otros temas. En el país, el desarrollo vino por el lado estructural por otra serie de razones. En cuanto al temario, tenemos todo el que queramos. Si hay ánimo de regular todo, pues todo se regula. El peligro detrás de eso está en que se estanque la tecnología. Ha habido críticos en el país a incompetentes”. Yo creo que más claro no se puede decir. Ese es el fin último claramente establecido. Históricamente se ha indicado que puede haber un conflicto de intereses en la construcción. Hay una utilidad a la cual se hace acreedor quien construye, lo cual es totalmente razonable para una actividad económica, como lo es para otras actividades. Lo grave es caer en la tentación de bajar una especificación para mejorar la utilidad y ahí radica la razón his-

tórica de la existencia de los códigos car concreto con él, si el concreto no 
la norma sismo resistente nuestra, quienes afirman que antes de que existiera había más responsabilidad de los ingenieros; tal vez eso es cierto. No existían unas reglas prescriptivas y obligatorias, pero sí era algo que se hacía y se miraba con seriedad. En el momento en el que aparece la norma, el objetivo se traslada a simplemente cumplir el mínimo que trae la norma y hay el peligro de que o la norma estanque las cosas o, se empiece a eludir un poco la responsabilidad bajo la premisa de que ya cumplí la norma y eso es todo.

\section{¿Cómo se adoptan los CÓDIGOS DE CONSTRUCCIÓN?}

Mundialmente esto varía. Los hay de adopción nacional, en algunos países ya vimos que, por ejemplo, en Estados Unidos la adopción es municipal, han tratado de moverla hacia adopción estatal; en el caso nuestro es nacional; en algunas latitudes se mezcla con la reglamentación urbana. La situación nuestra a través de la Ley 388/97 es clara. La parte urbana es resorte del municipio y va regido por esta ley diferente a la Ley 400/97 de sismo resistencia. La Ley

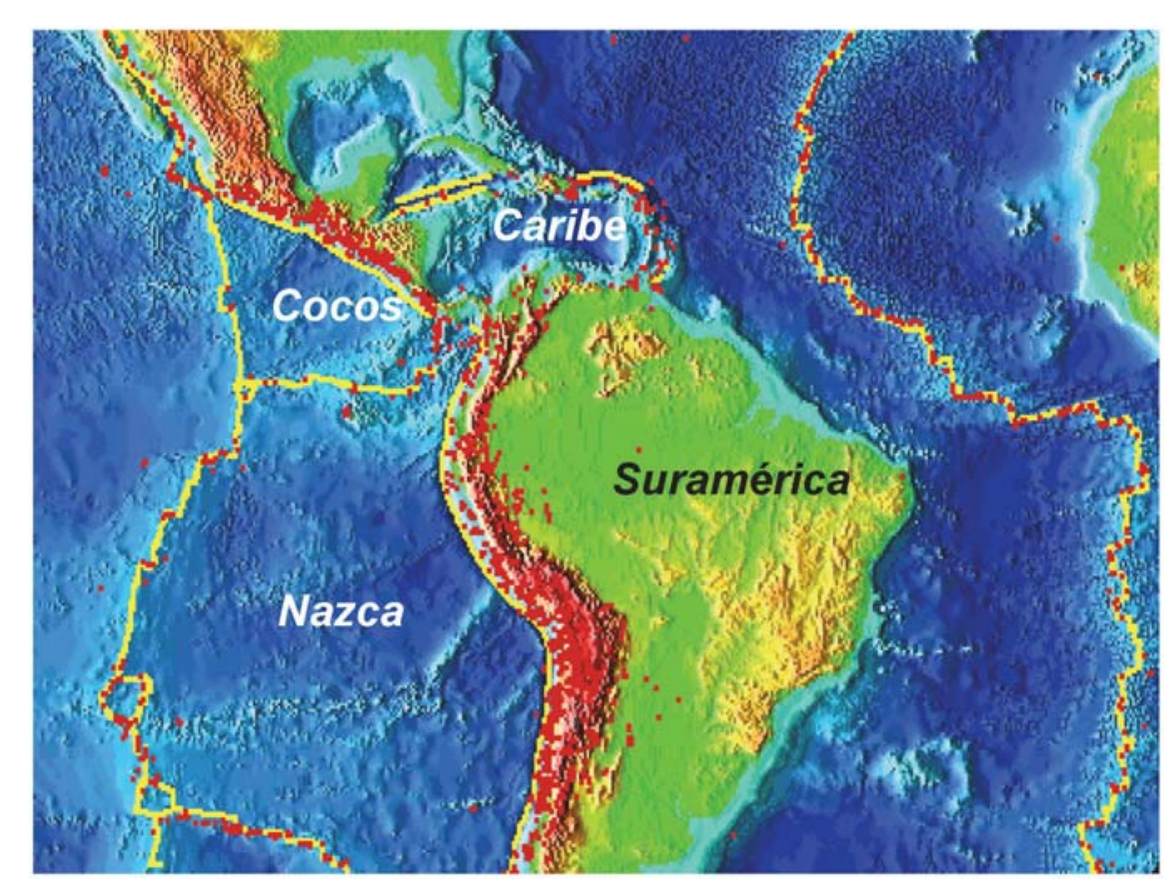

Figura 2. Localización tectónica de Colombia

388/97 se inspiró parcialmente en la ley urbana española, que solucionaba un problema, quizás hasta similar al nuestro, de la posguerra civil española y esto lo traen al país. Es el gran peligro que tenemos acá de copiar mucho de otros lados, pero a veces sin mucho criterio. De ahí que tengamos una normativa que tiene información de códigos europeos, norte americanos y de otros países. La Ley 400 de 1997 rige de forma obligatoria los criterios de sismo resistencia en todo el territorio nacional. Sin embargo, es importante ser conscientes de que tenemos un paquete compuesto por tres tipos de documentos: el código de construcción per se, que es la reglamentación de lo que es jurídicamente obligatorio, es un mínimo que se exige a la sociedad, es el contrato social que se mencionaba; luego esto se sustenta sobre unas normas técnicas que describen los materiales rigurosamente y que prescriben la manera como se fabrican y ensayan. Esta es la labor que hace el Instituto de Normas Técnicas y Certificación (ICONTEC) en el país y lo que hace la American Society for Testing and Materials (ASTM) dentro del medio norteamericano; y por último un tercer grupo consistente en las especificaciones de construcción. Este último grupo es algo que no se usa frecuentemente en el país. De hecho, una de las grandes falencias que tenemos es que muchos profesionales nacionales creen que porque entregan los planos ya todo está completo. Tan solo es la mitad. En el medio europeo o norteamericano, inclusive son más importantes las especificaciones que los planos. ¿Cómo se va a construir? ¿Qué es necesario cumplir durante la construcción? ¿Qué es lícito y qué no? Aunque los planos se llenen de notas, esto no funciona y tampoco estamos en manos de profesionales o personal auxiliar de construcción que conozca tanto todo como para saber qué es correcto. A veces se toman unos riesgos simplemente por desconocimiento de algo que debe ir en la especificación pero que no se usa en el país.

La creación del código de construcción en Colombia viene de una tragedia, el temblor de Popayán, y esto no es único a nivel mundial. La localización tectónica colombiana es interesante porque estamos sobre la placa suramericana, tocamos la placa Caribe por el Norte y la placa de Nazca por el Occidente (Figura 2).

\section{¿QUÉ TANTO SE MUEVEN LAS PLACAS TECTÓNICAS EN Colombia?}

Estas mediciones tienen algún tiempo, son mediciones de GPS (Figura 3). Allí se ve que la placa de Nazca se mueve con respecto a la placa suramericana 70 milímetros por año, eso quiere decir que son casi siete metros por siglo que Suramérica se mueve con respecto a la placa de Nazca en Colombia. La placa de Nazca subduce debajo de la placa Suramericana. La placa Caribe se mueve del orden de un centímetro por año contra la placa Suramericana. Este es un caso curioso porque estamos siendo comprimidos y eso nos da un reflejo de algo que es raro para un país andino y es que los ríos corren paralelos a los Andes. El río Magdalena nace casi en 


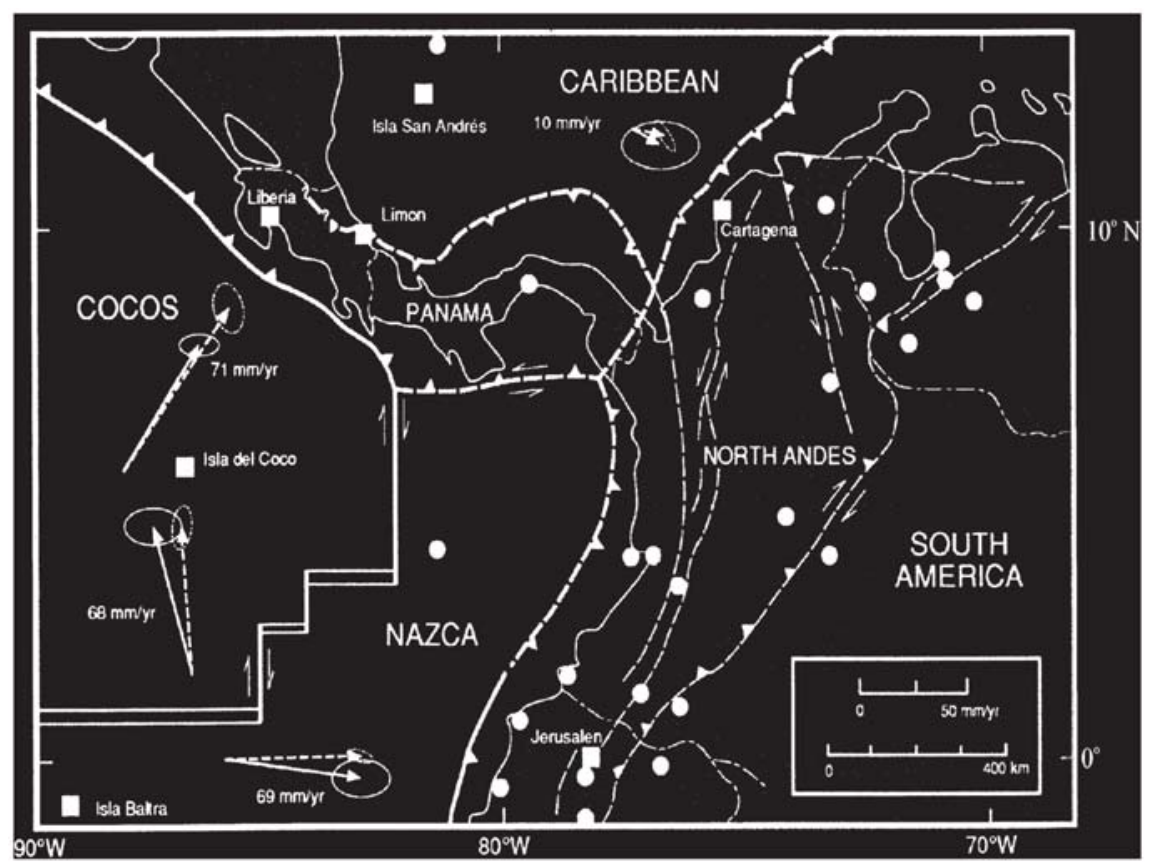

Figura 3. Movimientos relativos de las placas tectónicas en Colombia

la frontera con Ecuador, recorre 1500 kilómetros para salir al Caribe y esto se debe a las fallas geológicas. La mayoría de los grandes sistemas de fallamiento en el país tienen dirección norte-sur y los ríos corren encima de estas fallas.
En la Figura 4 se presentan la localización, la profundidad y la magnitud de los sismos registrados en Colombia y utilizados en la elaboración de los mapas de amenaza sísmica del Reglamento NSR-10. El color indica la

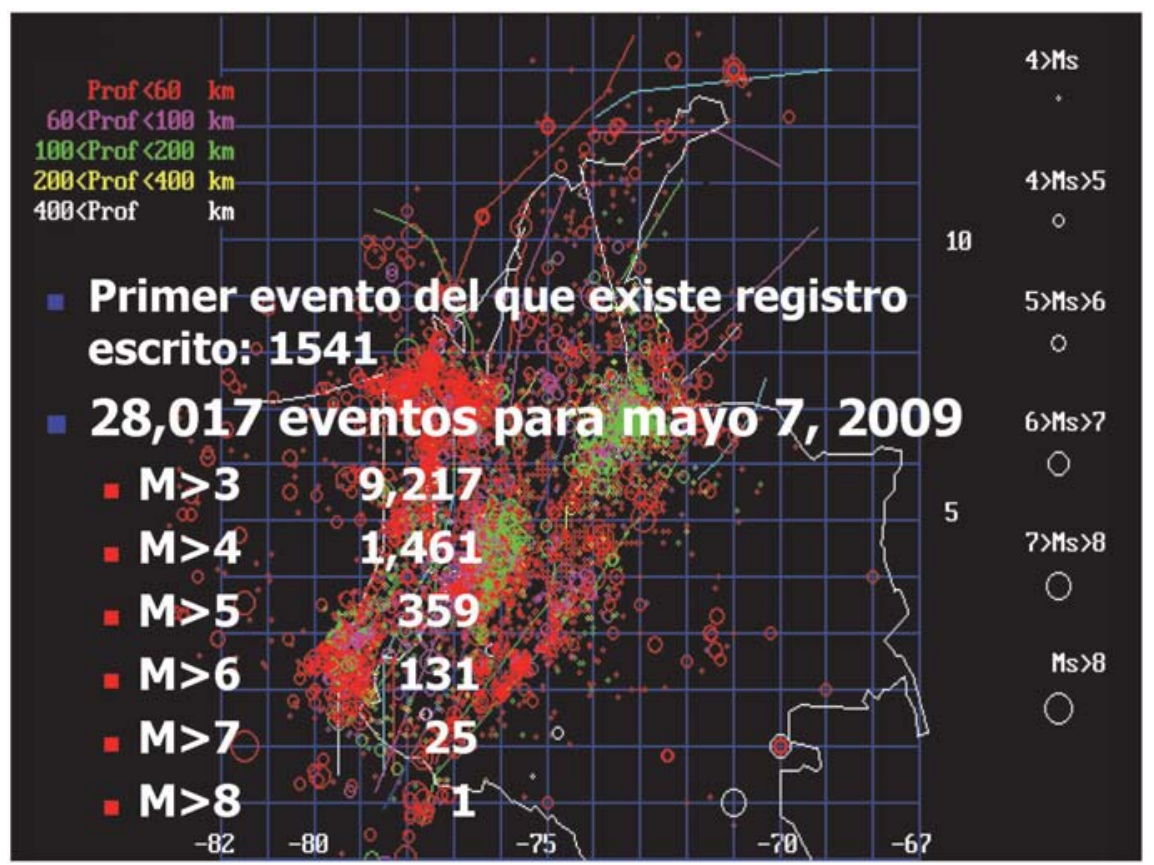

Figura 4 - Localización, profundidad y magnitud de los sismos registrados en Colombia y utilizados en la elaboración de los mapas de amenaza sísmica del Reglamento NSR-10 profundidad del sismo, el tamaño del círculo indica su magnitud. Esto es de una base de datos grande, moderna, en tiempo real, de buena calidad. Nos deben preocupar los sismos de color rojo (superficiales) y con círculo grande (magnitud alta). Lo de color verde corresponde a la zona volcánica en la cordillera central y a lo que se conoce como el nido de Bucaramanga, donde tiembla prácticamente a diario, magnitudes del orden de 6.5 y aproximadamente 150 kilómetros de profundidad y no producen daño ni aumenta la amenaza sísmica de Bucaramanga. La Universidad de los Andes ha participado en una serie de investigaciones sobre cuál es su origen. Nos preocupa también la zona de subducción, con eventos superficiales (en rojo) en la costa Pacífica y todo el sistema de fallamiento del pie de monte llanero, que corresponde a la frontera entre la cuenca del Orinoco y del Amazonas contra el bloque andino. Existe en él un vacío sísmico en frente de Bogotá cuyo último evento importante fue el sismo de Tauramena en enero de 1995. Para la norma NSR10 se dispuso de una base de datos con 28.000 eventos, la cual contiene más de 25 temblores magnitud 7, hay uno magnitud 8. La Red Acelerográfica Nacional del Servicio Geológico Colombiano (antiguo Ingeominas) opera más de 25 estaciones sismográficas y Bogotá tiene una red acelerográfica importante al igual que Medellín y Cali. Todos estos instrumentos nos ayudan a entender mejor la tectónica y sismología colombiana.

\section{ANTECEDENTES A LA NORMATI- VA SISMO RESISTENTE}

Primero, un fuerte temblor en Cúcuta en 1875. Después, el temblor del eje cafetero en 1979 resaltó numerosos problemas relacionados con acabados, fachadas, diseño de la estructura, golpeteo entre edificaciones vecinas que se ha regulado en la norma NSR-10 porque un edificio puede afectar al otro. Finalmente, el caso de Popayán. Dicen que todo temblor importante tumba una 
facultad de ingeniería, aquí se cayó la de la Universidad del Cauca. Esto es lo que la norma no quiere que ocurra. Una ciudad con 200000 habitantes y 200 muertos fue lo que nos llevó a la primera legislación sismo resistente.

\section{ESTRUCTURA DE LA NORMA}

La primera norma de sismo resistencia colombiana se expidió por medio del Decreto 1400 de 1984. Este fue un decreto de facultades extraordinarias, expedido al amparo de la Ley 11 de 1983 que hablaba sobre la reconstrucción de Popayán; duró vigente14 años. El pronóstico era que duraba vigente un mes porque aquí en Colombia los decretos de facultades extraordinarias los demandaban hasta por el tamaño del marco. El contenido: lo primero era lo sísmico, aunque lo usual era que esto se tratara dentro de las cargas de diseño. En este caso, por temor a que fuera demandado pues la autorización de la ley era para hacer una norma antisísmica (término que se dejó de usar hace años, ahora es sismo resistente, nada actúa contra el sismo) se puso en esta norma; más adelante, venía lo que normalmente viene en los códigos: cargas, concreto estructural, mampostería estructural, edificaciones de uno y dos pisos - esto es algo único a nivel mundial, es un código para diseñar y construir casas de uno y dos pisos - luego las estructuras metálicas y por último las sanciones. Se trató definitivamente de un código de estructuras.

\section{¿Cómo SE llegó ALLÁ?}

Unos primeros intentos en los años setenta de traducción del código de California realizada por la Asociación de Ingeniería Sísmica (AIS). Se difundió ampliamente, costaba cinco pesos. Luego aparece un documento muy importante en el medio norteamericano que es el ATC 3, publicado en 1977, es la nueva generación de códigos de sismo resistencia. Primero fue traducido por la AIS y se le dio amplia difusión. Después se hizo una adaptación dentro de un convenio entre la Universidad de los Andes y la Universidad de Illinois, en el cual participaron todos los profesores que habían trabajado en el proyecto ATC 3 de la Universidad de Illinois y unos profesores de la Universidad de los Andes. Este texto fue la base de los documentos que se adoptaron por medio del Decreto 1400 de 1984, algo que consideró la National Science Foundation de Estados Unidos como uno de los mejores ejemplos a nivel mundial de transferencia de tecnología racional. El ATC-3 se adaptó pensando en los problemas colombianos. Ese borrador lo adopta la AIS y genera un documento que se denominó Norma AIS100, adoptada en el Decreto 1400/84. Luego viene la Ley 400 de 1997 y bajo su amparo se expide en 1998 la norma sismo resistente NSR-98 de 1998 y luego en el 2010, la NSR-10.

¿Cuál era la alternativa? O íbamos al Congreso y los convencíamos de que dejaran sacar un decreto de facultades extraordinarias, que la Constitución de 1991 había limitado, o se propugnaba la adopción de una ley marco. Prevaleció la teoría de irnos por una ley marco y el resultado fue la ley 400 de 1997. Ahí viene una de las grandes tristezas con respecto al procedimiento legislativo. Durante 1997 el Congreso expide dos leyes que hicieron trámite en paralelo sin que interactuaran la una con la otra. Se expiden la ley 388/97 de desarrollo territorial y la ley 400/97 de sismo resistencia. Escasamente en la ley 400/97 se nombran las curadurías creadas por la Ley 388/97 debido a la ausencia de coordinación entre ellas. Más aun, la ley 400/97 salió del Congreso primero que la ley 388. La numeración la da la oficina jurídica de Presidencia cuando el Presidente sanciona la ley y en honor al decreto 1400 de 1984, a lo que se había hecho hacía catorce años, esperaron un mes a que llegara la nomenclatura de las leyes sancionadas al número 400 y por esto salió primero la 400 que la 388. Desafortunadamente, y todavía sufrimos las consecuencias, no iban coordinadas. Toda la parte de licenciamiento, licencias de construcción, qué se tramita en las curadurías, la creación misma de las curadurías viene de la ley 388. De la 400 viene lo de sismo resistencia. Por esta razón quedaron, obviamente, algunos vacíos.

\section{¿Cómo está Compuesta la REGLAMENTACIÓN DE SISMO RESISTENCIA COLOMBIANA?}

Está compuesta por la Ley 400/97, el Reglamento NSR que se expide al amparo de esa ley y las resoluciones que expide una comisión que crea la misma ley. Además, la Ley 400/97 incluye una facultad reglamentaria al presidente para expedir por decreto, como se ha utilizado dos veces, la reglamentación de sismo resistencia: en enero de 1998, la NRS-98, la cual duró vigente hasta el 15 de diciembre de 2010 y la NSR10 vigente en este momento, la cual ha tenido una serie de decretos reglamentarios que la actualizan, el último es de 2012. Esto es lo que está vigente como normativa sismo resistente en el país.

\section{¿QUÉ CONTIENE LA LEY 400/97?}

Primero una serie de definiciones, define qué es constructor, qué es una edificación, y otra serie de términos por ley. Con frecuencia se ven fallos de los tribunales que nunca consultan las definiciones que contiene la Ley 400/97. En seguida, vienen las responsabilidades y una serie de procedimientos para aprobar sistemas y materiales innovativos por medio de procedimientos relativamente sencillos. Luego, una cosa importantísima, la revisión de los diseños; muchos se quejan de la excesiva revisión, pero esto es mundial, hay que revisar y hay que hacerlo con gente competente. Eso no es que se muestren planos, se sellen y se construya, no debe ser así. Hemos tenido tragedias recientes gravísimas por simple falta de revisión. Más adelante, viene la obligación de la supervisión técnica de las construcciones, no solo lo que está en los planos, hay que ver que lo que se construya sea lo que es. Después define los profesionales afectados por eso. Les 
exige experiencia mínima y fija una manera para demostrar su idoneidad por medio de exámenes para demostrar que son competentes para las diferentes actividades profesionales cubiertas.

En este momento está listo el proyecto para empezar a llamar a los diferentes ingenieros que van cumpliendo los cinco años que se exigen, por ejemplo, para diseño estructural, a que presenten unos exámenes en que demuestren que conocen la normativa, no son solo de ingeniería. Próximamente empezarán a salir los decretos de convocatoria a estas pruebas, está en el plan del Ministerio de Vivienda y las conversaciones con el Instituto Colombiano para el Fomento de la Educación Superior (ICFES) están muy adelantadas, por lo que se llevara a cabo muy pronto. Estaremos viendo que van a llamar a los primeros grupos piloto para presentarse al examen y no van a poder firmar en la curaduría si no demuestran que lo han hecho. Los afectados son los ingenieros civiles y arquitectos, en lo que respecta a elementos no estructurales y a la parte de sismo resistencia; ingenieros mecánicos en lo que ellos están facultados para hacer; los supervisores, los revisores de proyectos, los diseñadores de elementos estructurales y no estructurales, todos van a tener que tomar el examen. Estaba en la normativa desde 1998 pero hasta ahora se van a realizar las pruebas.

Además de lo anterior, la Ley 400/98 crea una comisión asesora, comisión bastante compensada porque asiste el gobierno y algunas asociaciones profesionales. La clave de la ley 400 es la potestad reglamentaria donde el Congreso autoriza al Presidente a actualizar la norma por decreto con un visto bueno de la Comisión. Finalmente, contiene responsabilidades y sanciones y las disposiciones finales que fueron las que obligaron a rehabilitar todos los hospitales y otras edificaciones indispensables y de atención a la comunidad del país en zonas de amenaza sísmica intermedia y alta. Adicionalmente, hay unas sanciones muy claras ante el incumplimiento de la ley, por ejemplo, el alcalde puede mandar demoler una edificación que no cumpla la reglamentación, entre otros aspectos.

\section{¿QUIÉNES ASISTEN A LA CoMisión de Sismo RESISTENCIA?}

La Presidencia de la República, el Ministerio de Vivienda, el Ministerio de Transporte, Ingeominas, que ahora se llama, como antes, Servicio Geológico Colombiano, la Asociación de Ingeniería Sísmica, quien actúa como secretaria de la Comisión, la Sociedad Colombiana de Ingenieros, la Sociedad Colombiana de Arquitectos, la Asociación Colombiana de Ingeniería Estructural, la Cámara Colombiana de la Construcción (Camacol). Luego vienen dos personajes que nunca se han podido nombrar, uno por convocatoria, por prensa, la cual se ha hecho cuatro veces y no se ha presentado nadie, y por último un representante fijado por la ley Clopatosky, la cual nunca fue reglamentada. Para efectos prácticos, a la comisión asisten nueve personas. La Comisión se ha reunido 132 veces desde que se expidió la ley 400/97, más o menos, cada mes y medio. Se responden preguntas que sean realmente importantes, lo que tiene que ver con

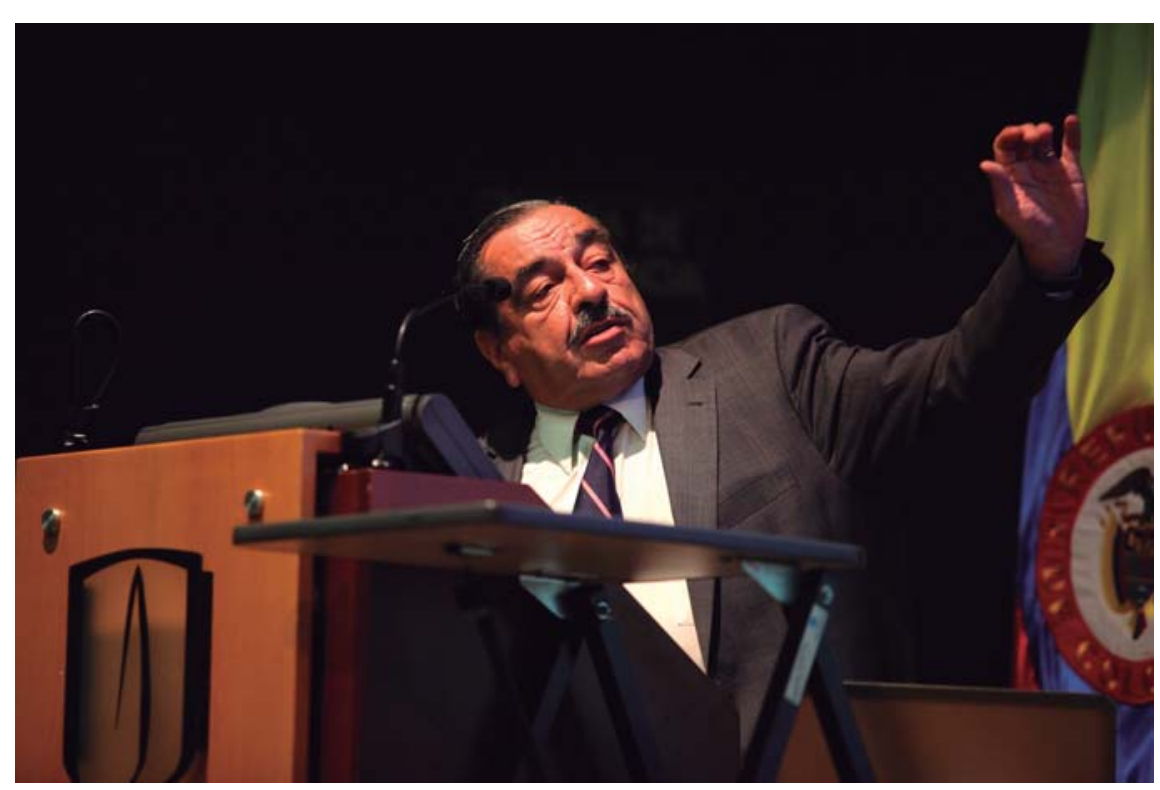

Luis Enrique García. Fuente: Archivo Particular, Universidad de los Andes

conocimientos que debe tener un profesional no se responde.

\section{¿QuÉ CONTIENE?}

El resultado de catorce años de buena experiencia con el Decreto 1400/84 y con una aceptación del medio hizo que la norma sismo resistente se volviera algo nacional que funcionó. A través de la Ley 400/97 se introdujeron otros temas adicionales a los cubiertos por la norma de 1984. Filosóficamente se incluyeron todos los temas que faltaban para que fuera un verdadero código de construcción. Dentro de ellos están estructuras de madera y guadua, estudios geotécnicos, el alcance de la supervisión técnica, requisitos para medios de evacuación, protección contra el fuego, requisitos para vidrios y otros temas. La Ley 400/97 incluye otros temas que no se han reglamentado todavía, como por ejemplo, condiciones de seguridad durante la construcción. La ley dice qué se puede incluir pero no qué se debe hacer. Esto fue lo que se pensó cuando se hizo el borrador de la ley 400/97, evolucionar con algo que había funcionado con éxito y llevarlo al código de construcción. En el temario que encuentran en la Ley 400/97 se cubre prácticamente todo lo que se requiere, tal vez lo 
único que falta, porque en esa época no estaba de moda, es la parte ambiental.

Hay un aspecto clave que debe ser entendido. La ley 400 es para protección de la vida; la protección de la propiedad es un producto indirecto, deseable, pero no obligatorio de la norma dado que per se acepta el daño. La norma es de defensa de la vida. Trata las edificaciones indispensables y al final establece procedimientos para defender en lo posible el patrimonio de los ciudadanos y del Estado. La Ley 400/97 dice que un edificio diseñado con lo que prescriba la ley debe poder verse afectado por temblores pequeños sin daño, temblores moderados sin daño estructural con daño en los acabados y un temblor fuerte sin pérdida de vidas. ¿Qué es un temblor fuerte, moderado? No lo define la ley. Pero de fondo está diciendo que va haber daño porque lo único que se diseña para no daño, para efectos de sismo resistencia, son las plantas nucleares. De resto, todo está basado en un daño controlado reparable en principio, ojalá deseable, pero el daño está allí. Si se está defendiendo la vida, así haya daño no se puede exigir por medio de una póliza de seguros que no exista este daño, hay una contradicción.

Es importante aclarar también que la Ley 400/97 es para edificaciones. Esta ley las define como construcciones que están ocupadas la mayoría del tiempo por seres humanos. Por ejemplo, un puente es una construcción, pero no es una edificación. La norma solo cubre edificaciones. Por último, se insiste en que contiene requisitos mínimos. Así son todos los códigos de construcción del mundo y primordialmente para edificaciones nuevas. Además tiene procedimientos de reparación y de rehabilitación para lo que se ha construido antes de la vigencia de la norma.

¿Qué hacemos con lo otro? Por ejemplo, con las instalaciones industriales. ¿Cómo las diseño? Existe un documento, la norma aplicada a lo que no son edificaciones. La norma AIS 180 incluye cómo se diseña una instalación industrial, así como el tema de los tanques, de los puertos, de otra serie de construcciones que no están cubiertas por la norma. Por otro lado, existe una reglamentación para los puentes expedida por el Instituto Nacional de Vías (INVIAS), que está siendo actualizada por la AIS y que reemplazará la reglamentación de 1995 basada en las mismas normas de la American Association of State Highway and Transportation Officials (AASHTO).

La supervisión técnica es obligatoria para toda edificación que tenga más de tres mil metros cuadrados. El Título E de casas de uno y dos pisos vino de una crítica al borrador de la norma de 1984. Algunas personas dijeron, en su momento, que para hacer hasta el crecimiento de un lote tocaba llamar a un ingeniero estructural. Ante esta crítica se trabajó en un documento que indicaba cómo hacer una casa de mampostería confinada hasta de dos pisos y eso ha estado desde la norma de 1984 como el título E. Existe toda una serie de publicaciones que usan otros países. Por ejemplo, Puerto Rico hizo una traducción de la cartilla "Manual de construcción, evaluación y rehabilitación sismo resistente de viviendas de mampostería”, que es precisamente cómo construir una casita de mampostería confinada sismo resistente segura, está con todos los procedimientos, está cómo evaluar si una existente funciona o no.

\section{Otras Reglamentaciones}

Dentro de lo complementario está la sobrerregulación a la que estamos dados los colombianos. Tenemos la ley 388/97 que estuvo en trámite en paralelo con la ley 400 sin ajustarse la una con la otra; la ley de bomberos, loable, porque trata de darles seguridad social a los bomberos. Sin embargo, cubre alcances superpuestos en muchos aspectos. Lo importante es que haya una sola reglamentación. Luego viene el Reglamento Técnico de Instalaciones Eléctricas (RETIE), el Reglamento Interno de Redes de Telecomunicaciones (RITEL), El Código Colombiano de Fontanería (NTC 1500) que es una norma del ICONTEC, lo cual es incorrecto porque la Constitución de 1991 reserva al legislativo la expedición de códigos y es la razón por la cual el Reglamento NSR no se denomina "Código" sino "Reglamento". La norma de 1984 se llamaba "Código Colombiano de Construcciones Sismo Resistentes” y hubo que convertirlo en Reglamento de Sismo Resistencia. Además hay otras normas como la Ley anti-trámite que es un decreto ley también autorizado por el Congreso. Allí se prohíben los códigos locales; eximen a la Aerocivil de tener que tramitar licencia de construcción y otros aspectos que afectan la reglamentación.

\section{REFERENCIAS}

American Concrete Institute (ACI), Instituto de Normas Técnicas y Certificación (ICONTEC) y Asociación de Ingeniería sísmica (AIS). (2002), Requisitos esenciales para concreto reforzado (para edificios de tamaño y altura limitados, con base en el ACI 318S-02). Farmington Hills: International Publication Series IPS-1.

Decreto 926 de 2010 (19 de marzo), por el cual se establecen los requisitos de carácter técnico y científico para construcciones sismorresistentes NSR-10. Diario Oficial No. 47.656.

Decreto 2525 de 2010 (13 de julio), por el cual se modifica el Decreto 926 de 2010 y se dictan otras disposiciones. Diario Oficial No. 47770.

Decreto 092 de 2011 (17 de enero), por el cual se modifica el Decreto 926 de 2010. Diario Oficial No. 47957.

Decreto 340 de 2012 (9 de julio), por medio del cual se hace un encargo.

Ley 400 de 1997 (19 de agosto), por el cual se adoptan normas sobre construcciones sismo resistentes. Diario Oficial No. 43.113.

Ley 1229 de 2008 (16 de julio), por la cual se modifica y adiciona la Ley 400 del 19 de agosto de 1997. Diario Oficial No. 47052. 